\title{
A mistagogia das ações litúrgicas em Cirilo de Jerusalém
}

\author{
The mystagogy of liturgical actions \\ in Cyril of Jerusalem
}

Rosemary Fernandes da Costa

\section{Resumo}

A compreensão de liturgia presente nas Homilias de Cirilo de Jerusalém e seus contemporâneos nos convida a resgatar o lugar teológico da liturgia na experiência cristã. Nesta concepção, a pessoa se identifica com Cristo em sua centralidade salvífica e a relação entre liturgia e vida sacramental é integrada. É uma experiência que potencializa a formação dos neófitos, pois nela se reúnem as condições da própria dinâmica da Revelação: a iniciativa de Deus, a ação sacramental, a configuração em Cristo Jesus, a revisão e mudança de vida, o testemunho e o compromisso comunitário-eclesial.

Deixando-nos conduzir por Cirilo de Jerusalém, observamos que os ritos litúrgicos têm valor sacramental. Não são apenas representativos, no sentido simbólico, mas são performativos, configurando cada fiel que experimenta a liturgia, em Cristo Jesus; ou seja, a centralidade destes é o valor sacramental, de inserção de cada pessoa e da existência humana, no Mistério pascal.

Em suas Catequeses, ao tratar da dimensão simbólica da liturgia, Cirilo conduz os neófitos para a grandeza do Mistério que é vivido. A participação de cada pessoa, de cada cristão, no Mistério pascal constitui não apenas um gesto singular, mas pela própria sacramentalidade das ações litúrgicas, participa da dinâmica da Revelação, a qual tudo conduz para o Reino de Deus.

Palavras-chave: Mistagogia. Cirilo de Jerusalém. Ação Litúrgica. Catequeses Mistagógicas. 


\begin{abstract}
The liturgy conception in the Homilies of Cyril of Jerusalem and his contemporaries invite us to rescue the theological place of the liturgy in Christian experience. In this conception, the person identifies himself with Christ in his salvific centrality and the relationship between liturgy and sacramental life is integrated. It is an experience that enhances the formation of the neophytes, as it brings together the conditions of the dynamic of Revelation: God's initiative, the sacramental action, the configuration in Jesus Christ, the review and change of life, the witness and the community-eclesial commitment.

Leaving us to lead by Cyril of Jerusalem, we note that the liturgical rituals have sacramental value. They are not only representative, but performative, configuring each faithful that experiments the liturgy in Jesus Christ, it means that the centrality of them is the sacramental value, that inserts each person and human existence, in the paschal Mystery.

In his Catecheses, speaking of the symbolic dimension of the liturgy, Cyril leads the neophyte to the greatness of the Mystery that is lived. The participation of each person, each Christian, in the paschal Mystery is not just a singular gesture, but through the sacramentality of liturgical actions, they participates in the dynamics of Revelation, which leads all to the Kingdom of God.
\end{abstract}

Keywords: Mystagogy. Cyril of Jerusalem. Liturgical Action. Mystagogical Catechesis.

\title{
Introdução
}

Os ventos renovadores do Concílio Vaticano II continuam soprando e convocam a Igreja ao diálogo permanente, à renovação humilde e focada em sua razão de ser: o mandato missionário deixado por Jesus Cristo. Novos documentos, sínodos, assembleias, procuram estar atentos à necessária reflexão e revisão das práticas pastorais, como também, da fundamentação teológica que as embasa e orienta. Um dos temas caros ao Concílio, brilhantemente expresso no Documento Sacrosanctum Concilium, foi o tema da Liturgia. O Concílio convoca todos os fiéis a resgatar o lugar fontal da Liturgia na vida cristã. Neste Documento, podemos observar as principais referências - a centralidade do Mistério pascal, a liturgia como "fonte" e 
"cume" da vida da Igreja, a missão da Igreja, o conceito de participação, a presença de Cristo na liturgia nos sacramentos, na Eucaristia, no celebrante, na Palavra de Deus, na assembleia reunida em seu nome. Enfim, o Concílio expressa no decorrer dessa belíssima redação teológico-espiritual, não apenas o embasamento teológico para a Reforma Litúrgica, mas o chão que fecundava o próprio Concílio.

Em unidade com a Igreja-mãe, desejamos, neste trabalho, não apenas fazer memória ativa e fecunda deste momento restaurador da vida eclesial e das relações entre Igreja e mundo, mas resgatar as fontes patrísticas que nutrem a vida da Igreja, conduzindo-a sempre amorosamente ao seu ponto de partida e à sua dinâmica de abertura e resposta à graça de Deus que tudo permeia e renova.

Neste artigo faremos um pequeno percurso, olhando em primeiro lugar, para a teologia que orienta e embasa as ações litúrgicas. E, em seguida, nos deixaremos conduzir por nosso mistagogo, Cirilo de Jerusalém, que, como pai amoroso, nos pega pela mão e nos apresenta o Mistério de Deus que se revela em nossas vidas nas ações litúrgicas.

\section{Um olhar sobre a teologia das ações litúrgicas}

Voltando nosso olhar para as fontes mais antigas e primeiras da tradição eclesiástica, encontramos uma experiência que não apenas é fundamento teológico para os Padres da Igreja, mas é seu alimento, sustento e orientação para a Liturgia e para a Iniciação Cristã: é a experiência mistagógica, presente desde os primeiros tempos do Cristianismo e sistematizada, sobretudo no catecumenato dos séculos III e IV.

Dentre as muitas acepções do termo mistagogia ${ }^{1}$, tornou-se recorrente

\footnotetext{
${ }^{1}$ Elencamos abaixo diversos sentidos para a mistagogia, a partir dos termos encontrados nas obras patrísticas do século III e IV: como iniciação ao Mistério; como instrução nos Mistérios divinos; como exposição dos significados da Sagrada Escritura; como orientação, guia no caminho misterioso de Deus; como o próprio Mistério que se revela; como a própria Sagrada Escritura; como ação sacramental - Batismo e Eucaristia; como celebrações dos ritos; como o tempo da Páscoa, incluindo o período quaresmal; como princípio fundante e dinâmico do sacerdócio; como Povo de Deus a caminho; como Igreja, sacramento de Cristo no mundo. T. Federici apresenta um esquema global detalhado do conteúdo mistagógico nos Padres da Igreja. Outro esquema excelente se encontra em BORNERT, R. Les commentaires byzantins de la Divine Liturgie du VII ${ }^{\circ}$. au $X V^{\circ}$. siècle. Paris: Institut français d'études byzantines, 1966, pp. 29-31. Cf. FEDERICI, T. "La Santa Mistagogia permanente de la Iglesia". Phase - Revista bimestral de Pastoral Litúrgica 193 (1993), pp. 194-195.
} 
a compreensão de mistagogia como tempo propício e como metodologia pedagógica da Iniciação ao Mistério. As Homilias Mistagógicas eram justamente reservadas a este tempo pascal para que os neófitos compreendessem o Mistério no qual já estavam inseridos, pois já haviam participado das ações litúrgico-sacramentais. Quanto ao Caminho catecumenal, este se refere mais à metodologia, às mediações que auxiliariam no processo de inserção do catecúmeno na dinâmica do Mistério.

Se há um lugar de excelência da experiência mistagógica, ele reside na liturgia. Na Tradição e no Magistério, a liturgia teve sempre o primado no que diz respeito à mistagogia. É na liturgia que o Mistério pascal se faz presente. Na interpretação do liturgista O. Casel:

A Liturgia não é apenas uma 'instituição' que nos veio de Cristo, mas é a continuação ritual do Mistério de Cristo. Em outras palavras, na liturgia, o próprio evento da salvação torna-se presente e ativo para os homens de todos os tempos e lugares e, consequentemente, toda ação litúrgica representa um suceder-se de momentos na história da salvação ${ }^{2}$.

A Liturgia não é um conjunto de lugares ou símbolos funcionais, mas é ação sacramental da presença salvadora de Jesus Cristo na Criação. Todos os elementos e pessoas reunidos são sinais, mediadores na comunicação simbólico-religiosa da liturgia. A Liturgia se dá na assembleia reunida, na Igreja. É ela também que dá à Igreja seu caráter de Mistério de Deus, "não apenas no sentido gnosiológico de uma verdade revelada, mas na sua acepção existencial, como realidade que em si mesma é objeto da nossa profissão "credo Ecclesiam' 3 ".

O termo 'Mistério' aponta para uma realidade desconhecida, íntima, oculta, uma presença por se revelar. No Cristianismo, o Mistério de Deus se revela à humanidade e convida a uma abertura existencial, que conduz tudo e todos à plena realização. É a História da Salvação, plenificada na encarnação, na redenção, na Páscoa de Jesus. É o Mistério pascal, ou Mistério de Cristo, Mistério da fé.

A liturgista I. Buyst apresenta dois momentos constitutivos do Mistério

${ }^{2}$ NEUNHEUSER, B.; MARSILI, S.; AUGÉ, M.; CIVIL, R. A Liturgia. Momento histórico da Salvação. São Paulo: Paulinas, 1986, p. 94.

${ }^{3}$ BOFF, Lina. Espírito e Missão na Teologia. Um enfoque histórico-teológico: 1850-1930. São Paulo: Paulinas, 1998, p. 110. 
pascal que se faz presente nas celebrações eucarísticas: a liturgia da Palavra e a liturgia sacramental.

Na liturgia, o Mistério pascal de Jesus se faz presente, em toda a sua densidade e extensão, atuando no rito litúrgico, na celebração memorial, principalmente na celebração eucarística. É o Mistério da fé presente $n a \mathrm{e}$ pela ação ritual que inclui: a narrativa e interpretação dos fatos - liturgia da Palavra -; e as ações simbólicas relacionadas com esses fatos - liturgia sacramental ${ }^{4}$.

A fonte deste saber reside na elaboração dos Padres da Igreja da liturgia recebida pelas tradições apostólicas ${ }^{5}$, em diálogo com as reflexões teológicas de seu tempo. A Palavra de Deus é fonte mistagógica e as ações litúrgicas são sinal e presença do próprio Cristo, mistagogia viva e fecunda para a comunidade eclesial que se reúne em torno deste altar. Desde estas releituras, podemos compreender mais facilmente os dois elementos mais constantes na concepção de 'mistagogia' nos Padres da Igreja: a liturgia sacramental e a sua explicação teológica.

Em Cirilo de Jerusalém, podemos encontrar estes dois elementos integrados nas ações litúrgico-sacramentais e, brilhantemente apresentadas em suas Homilias Mistagógicas. Na perspectiva ciriliana, o evento litúrgico é o centro de sua reflexão teológica e orientações catecumenais. Ele fala a partir das ações litúrgico-sacramentais, de dentro delas, elaborando uma teologia litúrgica e conduzindo os iniciantes à compreensão e participação consciente da realidade da qual se tornam partícipes pelos sacramentos da Iniciação Cristã. A Liturgia é a fonte e o lugar teológico para Cirilo de Jerusalém. É nesta experiência que o ser humano se identifica com Cristo em sua centralidade salvífica e inicia um processo de reconfiguração de toda a sua vida neste novo caminho.

Seguindo os passos de Cirilo, compreendemos a Liturgia como princípio mistagógico não apenas por seu princípio ativo - o Mistério pascal de Cristo - mas porque, a partir deste princípio, ela mobiliza todas as demais dimensões para uma mistagogia viva: a escuta da Palavra, a integração da pessoa inteira

\footnotetext{
${ }^{4}$ BUYST, I.; SILVA, J. A. O Mistério celebrado: memória e compromisso. São Paulo: Paulinas, 2004, pp. 82-83 (grifo nosso).

${ }^{5}$ Cf. BOLLIN, A.; GASPARINI, F. A catequese na vida da Igreja. São Paulo: Paulinas, 1998, p. 28.
} 
no Mistério da Salvação, a integração das relações fundamentais da pessoa (consigo, com os outros, com o mundo, com Deus), a revisão e mudança de vida, a partilha, o testemunho comunitário e o envio à missão

As ações litúrgicas são princípios mistagógicos, pois mobilizam a pessoa e a assembleia tanto como mediações para o encontro com o Mistério, como por tornarem presente à consciência e à realidade o Mistério pascal. Nesse aspecto, já podemos perceber as dimensões presentes nas ações litúrgicas, que são experimentadas e conduzem à integração pessoal e comunitária mas, principalmente, ao processo de abertura à dinâmica da Revelação, ao diálogo fecundo entre Deus e seu povo reunido.

A liturgia vai conduzindo a um caminho de integração em muitos níveis - entre caminho e meta, entre desejo e realização, entre o humano e o divino -, sempre possíveis por meio de uma participação existencialmente engajada. Sim, a participação é elemento fundamental para que este caminho realmente seja de abertura, acolhida ao Mistério revelado, como também de resposta pessoal e comunitária.

Este caminho mistagógico é eixo referencial no processo de iniciação cristã. E aqui não estamos tratando apenas do caminho catecumental, dos quais participam aqueles que estão se preparando para os Sacramentos de iniciação, mas, seguindo a compreensão dos Padres, "todos somos neófitos" $"$. Enfim, toda a comunidade vivencia um caminho iniciático, no sentido de aprendizagem permanente na dinâmica de abertura e resposta à Revelação.

Neste processo, não estamos diante de uma imposição, mas de um convite. Cada pessoa é convidada a fazer este caminho, a decidir livremente por esta acolhida do Mistério na sua vida por intermédio da comunidade sacramento: a Igreja. Assim sendo, as ações litúrgicas comunicam e já implicam conversão existencial e de atitudes. Por isso mesmo, configuram cada participante em Jesus Cristo, realizam a fraternidade e enviam à solidariedade com a Criação. É uma comunicação efetivamente transformadora da pessoa, da sociedade e do cosmos. Sua recepção é responsiva, pois suscitam uma resposta coerente, no seguimento de Jesus. É dinâmica, histórica, atualizadora, libertadora, integradora. É realização progressiva do projeto divino da salvação. "É dinamismo no qual cada pessoa se encontra com o Pai, por Jesus Cristo, no Espírito, o qual realiza

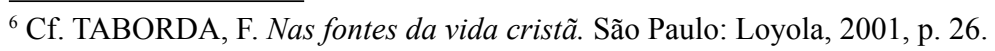


o seu desígnio salvífico sobre o homem e sobre a mulher"' É caminho mistagógico no qual o mediador é o próprio Cristo Jesus.

Através das ações litúrgicas, as pessoas são inseridas na trajetória da Tradição, os sinais tornam-se mediadores desta participação, convidam, convocam, performatizam à medida que são acolhidos na assembleia reunida. Os sinais tornam-se presença divina à pessoa, não uma presença virtual, mas uma presença mistagógica. Não se reduz a uma rubrica, a uma atitude interpretativa, a uma mimetização gestual. A Liturgia deve convocar a assembleia reunida a deixar-se conduzir à centralidade do Mistério que ali se realiza. $\mathrm{O}$ significado tradicionado na Liturgia se une à experiência viva dos fiéis reunidos em torno do altar.

Daí a importância de estabelecer a centralidade mistagógica entre os elementos litúrgicos, conduzindo à abertura sensível ao Mistério, de forma pessoal, comunitária, universal e cósmica. Os elementos presentes devem conduzir à inserção progressiva no Mistério de Deus que a todos envolve.

Podemos observar que em nossa sociedade, as realidades de tempo e de espaço vêm sofrendo uma revisão conceitual. No primeiro momento da modernidade, a ruptura com o passado tornou-se uma condição para o progresso moral, intelectual, econômico, social. Ou seja, chegou-se a crer que no futuro estaria a realização da sociedade e, para tanto, o desapego ao passado e à tradição se tornaria necessário. Esta concepção também afeta a comunidade eclesial e, muitas vezes, encontramos uma comunidade que expressa insatisfação, necessidade de produtividade, de eficácia visível, demonstrando uma projeção desta concepção de tempo e espaço utilitarista para as ações litúrgico-sacramentais.

Contudo, recordemos que na Liturgia a compreensão de tempo e espaço possuem outro sentido. O tempo é o tempo da Graça de Deus; passado, presente e futuro são tempo contínuo e não linear na liberdade da Graça e nas respostas da humanidade. Não se estabelece uma lógica de produtividade, de superação, de progresso, pois a Liturgia celebra o agir de Deus hoje e sempre ${ }^{8}$. É um tempo real e também escatológico. Nesse sentido, à medida que a liturgia torna-se experiência mistagógica, ela integra as dimensões de tempo-espaço e insere os fiéis nessa dinâmica. A assembleia reunida é participante do Mistério, protagoniza a liturgia e, a partir dessa experiência, potencializa a revisão de

${ }^{7}$ BOFF, Lina. Espirito e Missão na Teologia, op. cit., p. 110.

${ }^{8}$ Cf. TRIACCA, “A. M. Tempo y liturgia”. In: SARTORE, D.; TRIACCA, A. Nuevo Diccionario de Liturgia. São Paulo: Paulinas, 1984, pp. 1973-1974. 
sua existência, reinterpreta o mundo numa nova ótica e, consequentemente, constrói novos significados para suas escolhas e seu agir cotidiano?.

$\mathrm{Na}$ Liturgia, os conceitos de passado, presente e futuro ganham um novo sentido. O distanciamento cronológico é superado pela ideia de kairós, de tempo da Graça. É o caráter kairológico da salvação, sua acolhida e realização efetiva no hoje da história, acolhida que se torna sacramental, sinal salvífico para toda a história da humanidade ${ }^{10}$. Mistério que se revela numa propensão escatológica dinâmica que, por si mesmo, faz e refaz incessantemente sua leitura hermenêutica. Exige uma ausculta constante, atenta, contínua, sempre em busca de novas estruturações, novas compreensões que se anunciam a cada momento kairológico.

Vale à pena revermos aqui o texto integral do liturgista A. Triacca:

O tempo litúrgico é o tempo para o qual Cristo é 'tudo', ao passo que, concomitantemente, se continua o que no tempo Cristo fez e prossegue fazendo aos seus membros. Todo fiel, ao viver essa realidade e com essa atitude, está fazendo hoje a exegese existencial do Cristo ontem, hoje e sempre. Em um hoje perene, o tempo litúrgico tem a capacidade de ritmar e avaliar a existência do homem resgatada em um 'hoje da graça' em que a palavra de Deus se torna vida ${ }^{11}$.

Com relação ainda ao conceito de espaço, também este é reformulado na experiência litúrgica. Ali ocorre uma integração que aproxima espaços distantes no tempo cronológico e no espaço histórico-geográfico. A assembleia reunida está em unidade com toda a assembleia dos filhos e filhas de Deus de ontem, de hoje e de amanhã ${ }^{12}$. A Liturgia é ação histórica e meta-histórica. O caráter local integra-se ao dinamismo global, no sopro fecundo do Espírito de Deus. A Tradição é acolhida como fonte que nutre e renova a comunidade presente.

Enquanto lugar privilegiado da experiência mistagógica, a ação litúrgica fecunda uma relação entre a Igreja e o mundo ${ }^{13}$. A Igreja é o sacramento de salvação no mundo, comunicação do Mistério salvífico ao mundo. A ação

\footnotetext{
${ }^{9}$ Idem, p. 1982.

${ }^{10}$ Idem, p. 1974.

${ }^{11}$ Idem, p. 1987.

${ }^{12}$ Cf. CUVA, A. “Asamblea”. In: SARTORE, D.; TRIACCA, A. M. op. cit., p. 177; BUYST, I; SILVA, J.A. op. cit., p. 100.

${ }^{13} \mathrm{SC} 9$.
} 
litúrgica fecunda a vida nova de Cristo Jesus em cada fiel, e este, torna-se sinal, sacramento deste Mistério, no mundo ${ }^{14}$.

Pela ação litúrgica, a mistagogia não apenas é experimentada na assembleia reunida, como atinge toda a humanidade. O Mistério celebrado é princípio gerador da missão da Igreja, ou seja, de que a Boa Nova seja anunciada a todos os povos.

Enfim, a ação de Cristo na Liturgia, a inserção dos fiéis no Mistério pascal, e seu agir missionário no mundo, não são realidades distintas, mas em profunda comunhão. A Liturgia não é um momento de aprendizado ou de motivar uma intencionalidade cristã. As ações litúrgicas geram a vida nova, o seguimento de Jesus, a resposta missionária. Por outro lado, a missão reenvia à Liturgia, em um processo de crescimento na direção da plenitude da vida em Cristo.

\section{Conduzidos por Cirilo de Jerusalém}

Os Padres da Igreja ${ }^{15}$ orientavam a Iniciação Cristã como um caminho de introdução, abertura e diálogo com o Mistério, um caminho vital e de integração do ser humano em suas muitas dimensões. A mistagogia é compreendida como o fundamento e o caminho do processo. Ela é o grande referencial que inspira e ilumina este processo determinando a iniciativa, a centralidade e a meta do processo na dinâmica da Revelação entre Deus e a humanidade.

Uma das orientações fundamentais da experiência dos séculos III e IV para nossas comunidades é a profunda integração entre a espiritualidade, a liturgia e pedagogia. Essa integração é proporcionada devido ao embasamento teológico próprio desse período. Segundo E. Mazza, a mistagogia foi conhecida na tradição como a explicação teológica do fato sacramental ou dos ritos que compõem a celebração litúrgica, contudo, é muito mais do que um gênero literário ou uma metodologia pastoral-litúrgica: a mistagogia é a teologia dos primeiros tempos ${ }^{16}$.

\footnotetext{
${ }^{14}$ Cf. LODI, E. Liturgia della Chiesa. Bologna: EDB, 1981, p. 108.

${ }^{15}$ Encontramos textos basilares sobre essa experiência em: Basílio Magno (329-379), Gregório de Nissa (335-394) e Gregório Nazianzo (330-390), Cirilo de Jerusalém (315-387), Ambrosio de Milão (339-400).

${ }^{16}$ Cf. MAZZA, E. La Mistagogia. Una Teologia della Liturgia in epoca patristica. Roma: Centro Liturgico Vincenziano, 1988, p. 5.
} 
Em suas cinco Catequeses Mistagógicas ${ }^{17}$, Cirilo revela que a mistagogia é um caminho no qual ele se insere e também se vê interpelado a aprofundar. Neste percurso, Cirilo revela sua compreensão de mistagogia como momento interior ao Mistério, do qual ele procura explicitar e convidar cada neófito a acolher o dom de Deus que recebeu. A cada passo, Cirilo convida o neófito a experimentar a profunda comunicação de Deus na vida de cada pessoa, estabelecendo entre o neófito e Deus uma relação de proximidade e intimidade que se tornará, processualmente, seu referencial.

Evidenciamos, aqui, a exortação do Santo Padre Bento XVI, para a importância do resgate da sabedoria de Cirilo de Jerusalém, em sua integração entre a teologia e a ação pastoral.

Deste modo, a catequese de Cirilo, em virtude dos três elementos - doutrinal, moral e mistagógico - converte-se em uma catequese global no Espírito. A dimensão mistagógica se converte em síntese das duas primeiras, orientando-as à celebração sacramental, na qual se realiza a salvação de todo o homem. Trata-se, em definitivo, de uma catequese integral que implica o corpo, a alma e o espírito e continua sendo emblemática para a formação catequética dos cristãos de hoje ${ }^{18}$.

No contexto eclesial dos séculos III e IV, a liturgia é nuclear na formação e vivência do Cristianismo ${ }^{19}$ e Cirilo está em comunhão com seus contemporâneos nos processos de reflexão teológica e de orientação pastoral ${ }^{20}$. Neste embasamento, a dimensão pascal é central e, consequentemente, vigora o

\footnotetext{
${ }^{17}$ São atribuídos a Cirilo: as Catequeses Pré-Batismais, as Catequeses Mistagógicas, a Carta ao imperador Costanzo, o Sermão do Paralítico. Contudo, neste trabalho, privilegiaremos a concepção de liturgia presente nas Catequeses Mistagógicas.

${ }^{18}$ BENTO XVI. Audiência Geral. 27 de junho de 2007. Vaticano: Libreria Editrice Vaticana. Disponível em: 〈www.vaticano.va〉. Acesso em 19 de maio de 2015.

${ }^{19}$ Jerusalém tem um grande e inovador papel no desenvolvimento da liturgia na Igreja nascente, e Cirilo foi bastante responsável pela evolução dos ritos e expansão da liturgia que acontecia no IV séc. Jerusalém era uma exportadora de práticas litúrgicas para o resto do mundo cristão. Cf. DRIJVERS, J.W. Cyril of Jerusalém. Bishop and City. Boston: Brill, 2004, p. 71; CROSS, F. L. In: CYRIL OF JERUSALEM'S. Lectures on de Christian Sacraments. Londres: SPCK, 1951, p. XXXIV.

${ }^{20} \mathrm{Cf}$. YARNOLD, E. The awe inspiring rites of initiation. Baptismal Homilies of the fourth century. Grã-Bretanha: Saint Paul Publications, 1971. Neste trabalho Yarnold analisa a configuração dos ritos de Iniciação Cristã através das obras catequéticas de Ambrosio de Milão, João Crisóstomo, Cirilo de Jerusalém e Teodoro de Mopsuestia.
} 
cristocentrismo do processo de salvação, tanto no plano antropológico quanto cosmológico $^{21}$.

Para os Padres da Igreja, é a experiência litúrgico-sacramental que potencializa a formação dos neófitos. Nela se reúnem as condições da própria dinâmica da Revelação: a iniciativa de Deus, a ação sacramental, a configuração em Cristo Jesus, a revisão e mudança de vida, o testemunho e o compromisso comunitário-eclesial.

Os ritos litúrgicos têm, portanto, valor sacramental. Não são apenas representativos, mas são performativos, pois configuram crísticamente cada fiel que vivencia a liturgia. As Catequeses também nos falam do valor representativo e catequético dos ritos litúrgicos, mas a centralidade destes é o valor sacramental, de inserção de cada pessoa e da existência humana, no Mistério pascal $^{22}$.

O grande liturgista, E. Mazza ${ }^{23}$, explicita o enraizamento crístico na compreensão da liturgia e de seus ritos: "As ações de Cristo são portadoras de salvação, de sacramentalidade, como a imersão batismal, a nudez, que significa despir-se do homem velho. Não se trata de significados, mas de ações, de eventos que são portadores de salvação" 24 .

Cirilo trabalha com o conceito de mimesis, no sentido de imitação que configura a criatura naquele que é seu 'modelo'. Na dimensão pascal celebrada nos rituais litúrgicos, não apenas se faz memória, mas verdadeiramente se experimenta a mimesis do Cristo. Em Cirilo, imitação é identidade e, liturgicamente, identificação crística. É um conceito sacramental, que não indica o ritual na sua perspectiva visível, mas a dimensão interna e invisível da celebração ${ }^{25}$. Nas Catequeses a 'imitação’ experimentada através dos ritos litúrgicos, tem eficácia e valor sacramental.

No mesmo momento morrestes e nascestes. Esta água salutar tanto foi vosso sepulcro como vossa mãe. ${ }^{26}(\mathrm{CM} \mathrm{II}, 4)$

${ }^{21}$ Cf. RIGGI, C. In: CIRILLO DI GERUSALEMME. Le Catechesi. Roma: Città Nuova, $2^{\circ}$. Edição, 1997, p. 8.

${ }^{22}$ Cf. MAZZA, E. op. cit., p. 176.

${ }^{23}$ E. Mazza analisou a mistagogia como 'Teologia da Liturgia na época patrística', não apenas em Cirilo de Jerusalém, mas também em seus contemporâneos: Ambrosio de Milão, Teodosio de Mopsuestia e João Crisóstomo. Cf. MAZZA, E. op. cit.

${ }^{24}$ MAZZA, E. op. cit., pp. 176-177.

${ }^{25}$ Ibid., pp. 174-177.

${ }^{26}$ Diante das muitas edições críticas e traduções analisadas, observamos que o trabalho de F. 
Ora, vós vos tornastes cristos, recebendo o sinal do Espírito Santo, e tudo se cumpriu em vós em imagem, pois sois imagens de Cristo. (CM III,1)

$\mathrm{Na}$ liturgia ciriliana, observamos o quanto a corporalidade está integrada aos ritos, gestos, ganhando significado simbólico. A corporalidade, forte elemento da liturgia, torna-se sinal sacramental, princípio que dá sentido e integra a pessoa humana na sua totalidade ao Mistério pascal. Nesse sentido, a liturgia respeita a dimensão profundamente simbólica da pessoa humana em sua corporalidade, e oportuniza uma espiritualidade igualmente densa de significados, uma experiência que escapa à própria linguagem cognitiva.

A integração do corpo, dos gestos, é feita também com cuidado pedagógico, respeitando a passagem que é experimentada no ritual, conduzindo à sensibilidade pessoal e coletiva, mais do que a racionalidade, a fim de ultrapassar uma compreensão intelectual. Estamos também aqui diante de uma forte dimensão da mistagogia, vivida como experiência inenarrável, mas que é percebida interiormente e ganha uma memória única, a memória simbólica experimentada pela própria pessoa, em sua corporalidade.

Apenas alguns trechos para ilustrar essa dimensão, pois toda a liturgia sacramental é marcada por gestos, o que tornaria muito extensa essa descrição.

Entrastes primeiro no adro do batistério. Depois vos voltastes para o Ocidente e atentos escutastes. Recebestes então a ordem de estender a mão, e renunciastes a satanás como se estivesse ali presente. É preciso que saibais que na história antiga há uma figura deste gesto. (CM I,2) Logo que entrastes, despistes a túnica. E isto era imagem do despojamento do velho homem com suas obras. Despidos, estáveis nus, imitando também nisso a Cristo nu sobre a cruz. (CM II,2)

Depois de despidos, fostes ungidos com óleo exorcizado desde o alto da cabeça até os pés. Assim, vos tornastes participantes da oliveira cultivada, Jesus Cristo. (CM II,3)

Cirilo respeita uma antropologia, na qual o corpo, o entendimento, as emoções, não são elementos separados, mas integrados numa única experiência humana. Podemos dizer, em unidade com os liturgistas, que aqui há uma

Vier é o mais próximo do texto grego. Será, portanto, o texto de referência em nossas citações. Cf. CIRILO DE JERUSALEM. Catequeses Mistagógicas. Trad. F. VIER, introd. e notas F. FIGUEIREDO. Petrópolis: Vozes, 2004. 
experiência viva da sacramentalidade do corpo $^{27}$, na medida em que, os gestos não são meras repetições ou mímicas, mas são vividos simbolicamente, inseridos no Mistério litúrgico, e integrando a pessoa ao Mistério de Deus que a todos envolve.

As Catequeses Mistagógicas procuram ajudar o neófito a compreender o significado dos gestos corporais que experimentou sacramentalmente, contudo, essa experiência fala por si, a cada neófito. Portanto, ao tratar da dimensão simbólica da liturgia, o que Cirilo intenta é construir uma linguagem que não visa definir a experiência, mas orientar para a grandeza do Mistério que é vivido.

Esta dimensão não tem caráter individualista, portanto, lembramos mais uma vez, o cuidado pedagógico de Cirilo no traçado da História da Salvação e da Tradição eclesial, associando cada gesto à representação e significado bíblico, ao Mistério de participação no corpo místico de Cristo, e na Igreja, corpo comunitário, sociedade visível e testemunha do Mistério na humanidade.

Outro aspecto fundamental na concepção de Liturgia presente em Cirilo é o conceito de koinonia. Cirilo faz uso recorrente deste termo, no sentido de participação, para definir a relação entre o rito sacramental e o evento salvífico da Páscoa de Cristo. O termo koinonia é mais do que um simples termo pronunciado nas Catequeses, pois marca uma chave de leitura para compreensão da experiência vivida na liturgia sacramental ${ }^{28}$.

O óleo exorcizado era símbolo, pois, da participação da riqueza de Cristo. (CM II,3)

Talvez dissesse estas coisas por causa de alguns, dispostos a ver o batismo como prodigalizador da remissão dos pecados e da adoção, mas não como participação, por imitação, dos verdadeiros sofrimentos de Cristo. (CM II,6)

Vós fostes ungidos com o óleo, feitos partícipes e companheiros de Cristo. (CM III,2)

Desse modo, 'tornamo-nos partícipes da natureza divina'. (CM IV,3)

O conceito de participação no Mistério pascal é um eixo mistagógico. A celebração torna sacramentalmente presente o Mistério salvífico a que

${ }^{27}$ Cf. LAFONT, G. “A experiência espiritual e o corpo”. In: GOFFI, T.; SECONDIN, B. (Orgs.). Problemas e perspectivas de Espiritualidade. São Paulo: Loyola, 1992, p. 16.

${ }^{28}$ Cf. MAZZA, E. op. cit., pp. 179. 
faz referência: a Páscoa de Jesus Cristo. Na liturgia, o neófito experimenta verdadeiramente a plenitude da vida cristã 'por meio' e 'na' celebração eucarística.

Para a patrística, a liturgia é o culto da Igreja, integrado no marco dos Mistérios da Salvação. As ações litúrgicas são compreendidas como celebração do Mistério de Cristo; ritos que, em seu acontecer simbólico, manifestam, fazem presente e comunicam a morte e ressurreição do Senhor ${ }^{29}$. A participação de cada pessoa, de cada cristão, no Mistério pascal constitui não apenas um gesto singular, mas pela própria sacramentalidade dos atos litúrgicos, participa da dinâmica da Revelação, a qual tudo conduz para o Reino definitivo, levando à plenitude a Igreja que caminha e, por seu envio e testemunho, toda a humanidade.

Ainda integrado com este conceito tão recorrente nas Catequeses Mistagógicas, o tema da participação nos conduz a uma visão eclesiológica. As instruções são realizadas em âmbito comunitário, assim como os sacramentos e toda a sua pregação integra o processo pessoal ao comunitário e, este, à dinâmica da História da Salvação, em unidade com todo o povo de Deus. Também as orações refletem essa visão eclesiológica, abrangendo a unidade de todos os fiéis e a comunhão dos santos.

Cirilo está sintonizado com o vínculo entre liturgia e comunidade, entre comunidade local e comunidade universal. Não compreende a liturgia como um momento isolado no campo pessoal ou no campo da igreja local. As ações litúrgicas são experimentadas e interpretadas como celebrações eclesiais, como sacramento de todo o Povo de Deus eleito e peregrino na história rumo ao horizonte escatológico.

O sentido de pertença eclesial indica vários elementos: o sacerdócio comum, a identidade cristã, o aspecto testemunhal e missionário, o aspecto hermenêutico, o caráter dialógico da dinâmica da Revelação.

Há ainda um aspecto fundamental que não podemos deixar de demarcar na concepção de Liturgia nesse mistagogo: é sua compreensão quanto à Sagrada Escritura no eixo catequético e litúrgico.

Para ele, a escuta da Palavra de Deus não é uma escolha metodológica, mas a chave da dinâmica da Revelação, o princípio e o fim do anúncio revelado e sempre presente na Criação e Redenção. Cirilo proclama a Palavra criadora, sentido e Mistério de Deus revelado. A História da Salvação é o fio narrativo,

${ }^{29}$ Cf. GUTIÉRREZ-MARTÍN, J. L. Belleza y misterio. La liturgia, vida de la Iglesia. Navarra: Eumsa, 2006, p. 74. 
pelo qual o próprio Deus vai conduzindo seus filhos e filhas na história e para além da história.

Poderíamos nos perguntar: qual o momento para a hermenêutica da Palavra? Qual seria o processo mistagógico? Experimentar o Mistério pascal e só depois buscar compreender e interpretá-lo através da Palavra? Ouvir a Palavra e compreendê-la para melhor saborear o Mistério do qual participa?

Cirilo tem dois procedimentos, antes e depois da experiência sacramental. Nas Catequeses Pré-Batismais, Cirilo prepara os neófitos para o Mistério que irão experimentar através do caminho da Sagrada Escritura. Ela é a mestra, é fonte que revela os conteúdos doutrinais a serem trabalhados. O eixo que dá consistência e orienta a linguagem, os exemplos e o diálogo com a realidade, na direção da inserção progressiva no Mistério de Cristo e na Igreja, é a mistagogia. Após os sacramentos da Iniciação, nas Catequeses Mistagógicas, Cirilo desenvolve a catequese a partir da experiência litúrgico-sacramental. Trata-se da mistagogia na liturgia sacramental, momento de imersão da pessoa inteira no Mistério pascal do qual participa.

$\mathrm{Na}$ primeira etapa, constatamos que a primazia pertence à Sagrada Escritura, ela é a base sólida para a experiência sacramental. Na segunda etapa, o elemento catequético encontra-se posterior à experiência, e não como uma função preparatória. Aqui subjaz a compreensão da liturgia como experiência fundadora da catequese.

Com relação a esta articulação entre catequese e liturgia, Villepelet defende que "não somos nós que entramos no Mistério da fé cristã, é o Mistério que vem até nós!" 30 . Se concordarmos com esse pensamento, a mistagogia propõe a acolhida do primado da Revelação plena em Jesus Cristo e, por ele, deixar-nos conduzir ao Pai. "Se considerarmos que a liturgia é a ação privilegiada da Igreja pela qual é atualizada, permanentemente, a Páscoa de Cristo, ela se torna um momento estruturador de toda catequese, é uma mediação essencial da mesma"31.

Segundo a tradição patrística, quanto mais viva e vivida é a liturgia, tanto mais necessita de catequese. Tem força mistagógica, pois nos conduz para a experiência de aliança e comunhão no e com o Mistério. Ela é acompanhamento, discernimento, compreensão, disposição da pessoa diante do caminho da fé cristã.

${ }^{30}$ VILLEPELET, D. "La liturgie comme médiation de la catéchèse". In: La Maison-Dieu. Catéchese et liturgie en dialogue. Paris, 2003, 234, p 67.

${ }^{31}$ VILLEPELET, D. op.cit. 
Ainda um aspecto que ressalta nas ações litúrgicas dos Padres e também está presente em Cirilo é o zelo com o processo de conversão. Uma das ações litúrgicas que expressa privilegiadamente este cuidado são os ritos de exorcismos.

A Iniciação Cristã primitiva tem esse aspecto como condição para a acolhida na comunidade e no processo de formação cristã. Cirilo tematiza a conversão em vários momentos das Catequeses Mistagógicas. Fala de mudança radical, de passagem do homem velho ao homem novo, nascido em Cristo, fala da presença do mal como caminho antagônico àquele do qual o neófito participa pelos sacramentos. Também os rituais litúrgicos possuem forte acento no exorcismo, no fortalecimento contra o mal, contra satanás, suas obras e cultos $^{32}$.

Os exorcismos têm particular importância, enquanto momento de fortalecimento da pessoa e de abertura para a 'escuta' da Palavra de Deus na própria vida. Assim, a responsabilidade e o compromisso do iniciante são fundamentais, mas sempre como resposta e cooperação à iniciativa de Deus. Os ritos de exorcismos são compreendidos como ações litúrgicas e, enquanto tais, celebram a ação de Deus e o processo de conversão e crescimento na fé dos catecúmenos. O liturgista J. Ariovaldo Silva nos ajuda a compreender o sentido dos exorcismos para a Patrística.

Confia-se no poder libertador de Deus, pedindo-lhe a intervenção para que, na caminhada preparatória para o sacramento da regeneração, expulse do catecúmeno todos os males, vícios, apego aos ídolos, defeitos de caráter, personificados pela figura de Satanás como raiz desses males. E que o espaço dela seja ocupado pelo Espírito de Cristo, o Espírito Santo. No fundo, é a proclamação da soberania de Deus sobre todo Mal existente, acolhida pouco a pouco pelo catecúmeno, à medida que vai conhecendo Jesus Cristo ${ }^{33}$.

A força e o amor libertador de Deus potencializam a superação de todo o mal e fortalecem o neófito neste combate.

\footnotetext{
${ }^{32}$ Cf. YARNOLD, E. The awe inspiring rites of initiation. op. cit., p. 20.

${ }^{33}$ SILVA, J. A. "A Iniciação Cristã em sua evolução histórica. Alguns apontamentos para estudo”. In: COMISSÃO REGIONAL DA DIMENSÃO LITÚRGICA DO NORDESTE 3. Liturgia e Inculturação. Paulo Afonso (BA): Fonte Viva, 2006, p. 87.
} 


\section{Conclusão}

Nos limites deste trabalho, desejamos demarcar a mistagogia como o grande eixo referencial na práxis litúrgica de Cirilo de Jerusalém. Elencamos algumas características, mas, se nos deixarmos conduzir por Cirilo passo a passo, observaremos muitas outras, pois todo o seu caminho é inspirado e orientado por esta visão teológica que também é sua experiência mística.

De certa forma, os Padres são posteriores a eles mesmos, pois a teologia mistagógica é outra forma de ver os sacramentos. Abre espaço para a teologia do mistério que se apresenta de um modo melhor para descrever o realismo sacramental como presença do evento salvífico no rito litúrgico ${ }^{34}$.

Não afirmamos que Cirilo tivesse consciência deste enraizamento nas suas orientações catequéticas, ou mesmo uma teologia mistagógica sistematizada. O que percebemos é que este referencial está presente em seu trabalho teológico-pastoral. Com o propósito de desenvolver as orientações catequéticas, promover a Iniciação Cristã de forma integral e fiel à Sagrada Escritura e à caminhada eclesial, Cirilo reúne dimensões que se configuram em uma mistagogia viva.

Em unidade com os Padres da Igreja de seu tempo, concebe a liturgia como fonte da experiência mistagógica, como lugar privilegiado de encontro, diálogo e configuração crística. Os sacramentos ganham seu sentido na liturgia. Não há significado sacramental fora da liturgia, fora da comunidade de fé que experimenta o Mistério pascal na liturgia.

(...) Mas como bem sei que a vista é mais fiel do que o ouvido, esperei a ocasião presente, para encontrar-vos, depois desta grande noite, mais preparados para compreender o que se vos fala e levar-vos pelas mãos ao prado luminoso e fragrante deste paraíso. (CM I,1)

A Iniciação ao Mistério não tem, dessa forma, seu lugar privilegiado nas catequeses, nos ensinamentos, mas na própria celebração litúrgica. Os ensinamentos tornam-se um ouvir, acolher, interpretar, reviver para compreender. É um movimento secundário, a fim de melhor mergulhar no Mistério que se vivencia. A experiência do Mistério, ou seja, a experiência mistagógica, é mais eficaz do que todos os argumentos e ensinamentos doutrinais.

$\overline{{ }^{34} \text { MAZZA, E. op. cit., p. } 8 .}$ 


\section{Referências bibliográficas}

BENTO XVI. Audiência Geral. 27 de junho de 2007. Vaticano: Libreria Editrice Vaticana. Disponível em: 〈www.vaticano.va〉. Acesso em 19 de maio de 2015.

BOFF, Lina. Espirito e Missão na Teologia. Um enfoque histórico-teológico: 1850-1930. São Paulo: Paulinas, 1998.

BOLlin, A.; GASPARINI, F. A catequese na vida da Igreja. São Paulo: Paulinas, 1998.

BUYST, I.; SILVA, J. A. O Mistério celebrado: memória e compromisso. São Paulo: Paulinas, 2004.

CIRILO DE JERUSALEM. Catequeses Mistagógicas. Trad. F. VIER, introd. e notas F. FIGUEIREDO. Petrópolis: Vozes, 2004.

CONCÍLIO VATICANO II. Constituição Sacrosanctum Concilium sobre a Sagrada Liturgia, 1965. Petrópolis: Vozes, 1966.

CROSS, F. L. In: CYRIL OF JERUSALEM'S. Lectures on de Christian Sacraments. Londres: SPCK, 1951.

DRIJVERS, J.W. Cyril of Jerusalém. Bishop and City. Boston: Brill, 2004.

FEDERICI, T. "La Santa Mistagogia permanente de la Iglesia". Phase Revista bimestral de Pastoral Litúrgica 193 (1993).

GUTIÉRREZ-MARTÍN, J. L. Belleza y misterio. La liturgia, vida de la Iglesia. Navarra: Eumsa, 2006.

LAFONT, G. “A experiência espiritual e o corpo”. In: GOFFI, T.; SECONDIN, B. (Orgs.). Problemas e perspectivas de Espiritualidade. São Paulo: Loyola, 1992.

LODI, E. Liturgia della Chiesa. Bologna: EDB, 1981.

MAZZA, E. La Mistagogia. Una Teologia della Liturgia in epoca patristica. Roma: Centro Liturgico Vincenziano, 1988.

NEUNHEUSER, B.; MARSILI, S.; AUGÉ, M.; CIVIL, R. A Liturgia. Momento histórico da Salvação. São Paulo: Paulinas, 1986.

RIGGI, C. In: CIRILLO DI GERUSALEMME. Le Catechesi. Roma: Città Nuova, $2^{\circ}$. Edição, 1997. 
SARTORE, D.; TRIACCA, A. Nuevo Diccionario de Liturgia. São Paulo: Paulinas, 1984.

SILVA, J.A. "AIniciação Cristãem sua evoluçãohistórica.Alguns apontamentos para estudo". In: COMISSÃO REGIONAL DA DIMENSÃO LITÚRGICA DO NORDESTE 3. Liturgia e Inculturação. Paulo Afonso (BA): Fonte Viva, 2006.

TABORDA, F. Nas fontes da vida cristã. São Paulo: Loyola, 2001.

VILLEPELET, D. "La liturgie comme médiation de la catéchèse". In: La Maison-Dieu. Catéchese et liturgie en dialogue. Paris, 2003.

YARNOLD, E. The awe inspiring rites of initiation. Baptismal Homilies of the fourth century. Grã-Bretanha: Saint Paul Publications, 1971.

Rosemary Fernandes da Costa

Doutora em Teologia pela Pontifícia Universidade Católica do Rio de Janeiro Professora de Cultura Religiosa na Pontifícia Universidade

Católica do Rio de Janeiro

Rio de Janeiro / RJ - Brasil

E-mail: rosenandescosta@gmail.com

Recebido em: 21/05/15

Aprovado em: 10/06/15 